\title{
Frequency, Etiology and Pattern of Midface Fractures
}

\author{
Javeria Azam ${ }^{1}$ \\ Jawad Safdar Rana ${ }^{2}$ \\ Humayun Kaleem ${ }^{3}$
}

\author{
BDS \\ BDS, MDS, PhD \\ BDS, FCPS
}

\begin{abstract}
OBJECTIVE: To determine the frequency, etiology and pattern of midface fractures in patients presented at Baqai Dental College.

METHODOLOGY: This study was carried out in the Department of Oral and Maxillofacial Surgery at Baqai Dental College, Karachi from January 2009 to March 2016. The study included 45 patients. After the confirmed diagnosis the patients were categorized on the basis of age, gender, etiology and type of fractures. The data collected was analyzed using SPSS statistical package.

RESULTS: The mean age of the patients presented with midface fractures was $28.58 \pm 9.992$ years. The study included $86.7 \%$ male and $13.3 \%$ female. The most common cause in the study was found to be road traffic accident (RTA) with $57.8 \%$. As much as $62.3 \%$ of the fractures were zygomatic followed by other type of fractures. CONCLUSION: This study revealed the high predilection of male as compared to female. Also the main cause of the fractures was found to be road traffic accident. Whereas zygomatic fractures were the most common fractures with highest percentage.
\end{abstract}

KEY WORDS: Midface fractures, Etiology, Zygomatic \& frequency.

HOW TO CITE: Azam J, Rana JS, Kaleem H. Frequency, etiology and pattern of midface fractures. J Pak Dent Assoc 2018;27(3):106-09.

DOI: https://doi.org/10.25301/JPDA.273.106

Received: 08 February 2018, Accepted: 20 May 2018

\section{INTRODUCTION}

$\mathrm{M}$ axillofacial injuries fall in the category of most commonly reported cases in Oral and Maxillofacial Surgery departments. ${ }^{1}$ As midface represents the middle part of the face including maxilla, nasal cavity, zygomatic bone, ethmoid bone, sphenoid bone and orbits. Injuries to Midfacial area can affect both soft tissue and skeletal structures. ${ }^{3}$ Fractures of Midfacial area may be isolated or together with other system injuries and their pattern is greatly influenced by age, gender, etiology and geographic location. ${ }^{2}$ This results in severe morbidity, disfigurement and malfunctioning like sensory disturbance, malocclusion, ocular dysfunction etc. ${ }^{1,13}$ Thereforemaxillofacial fractures are mainly considered and treated to reestablish the function and aesthetics according to the pattern of fracture and involvement of other adjacent

1. House officer Department of Oral and Maxillofacial Surgery, Baqai Dental College, Baqai Medical University, Karachi, Pakistan.

2. Assistant professor, Department of Oral and Maxillofacial Surgery, Dow Dental College, Dow University of Health Sciences, Karachi, Pakistan.

3. Assistant professor and Head of Department of Oral and Maxillofacial Surgery, Baqai Dental College, Baqai Medical University, Karachi, Pakistan.

Corresponding author: "Dr. Javeria Azam”<djaveriaazam395@gmail.com> structures. ${ }^{14}$

Injuries to facial region may involve single bone or combination of multiple bones. Some authors have stated zygoma as more vulnerable bone than maxilla in related to facial injuries. ${ }^{17}$

When it comes to age distribution midfacial fractures can be seen in all age groups. But patients in second and third decade of life have reported more. ${ }^{3}$

The etiologies of maxillofacial fractures vary from one geographical location to another due to social, economical, cultural consequences, awareness of traffic regulations and also among different age groups. ${ }^{12}$ There are multiple causes of midface fractures including road traffic accidents, falls, violence and sports injuries. ${ }^{2}$

To investigate this group of patients, this study was conducted to analyze the frequency, etiology and pattern of midface fractures at Baqai Dental College.

\section{METHODOLOGY}

Medical records of patients treated for midfacial fractures in the Department of Oral and Maxillofacial Surgery at Baqai Dental College, from January 2009 to March 2016, were 
obtained. All the records were analyzed in detail and data concerning patient's gender, age, prevalence, bone involved and etiology was extracted. As the legal requirement, informed consent was taken from all the participants before collecting the concerned data and for this purpose they were informed about all the aspects of study in detail. This study was approved on 2nd February 2016 by the institution review board of Baqai Dental College.

All clinically and radiographically confirmed mid-face fracture patients either having complex fractures including multiple bones or isolated bone fractures were included in this study. Exclusion criteria were patients with mandibular fractures, incomplete records and patients who refused to be treated. So study included forty-five patients out of which six were female and thirty-nine male.

Midfacial fractures were classified into maxillary (Le Fort I, II and III) fractures, zygomatic fractures, orbital floor fractures and combinations of these fractures. These were classified according to the maxillary-midface system of Lefort. ${ }^{16}$ Further etiology of the midface fractures was classified as Road traffic accidents (RTA), violence, falls and sports injuries.

Data were analyzed using Statistical Package for Social Sciences (SPSS) version 22.0.

\section{RESULT}

The records of 45 patients were analyzed. In this study $39(86.7 \%)$ were males and $6(13.3 \%)$ were females, with a male to female ratio of $6.5: 1$. The mean age was $28.58 \pm 9.992$ years, ranging from 10 to 60 years. As much as $62.3 \%$ of injuries were zygomatic fractures, this was followed by other types of fractures as shown in Table 1. Road traffic accidents with $57.8 \%$ tend to be the most frequent cause along with fall, violence and sports injuries mentioned in Table 2.

Table 1

\begin{tabular}{|c|c|c|}
\hline \multicolumn{3}{|c|}{$\begin{array}{l}\text { Distribution of the patients according to type of } \\
\text { fractures }\end{array}$} \\
\hline Etiology & Frequency & Percentage \\
\hline Combination & 3 & 6.7 \\
\hline Maxillary Lefort I & 2 & 4.4 \\
\hline Maxillary Lefort II & 10 & 22.2 \\
\hline Orbital & 2 & 4.4 \\
\hline Zygomatic & 28 & 62.3 \\
\hline Total & 45 & 100.0 \\
\hline
\end{tabular}

Table 2

\begin{tabular}{|c|c|c|}
\hline \multicolumn{3}{|c|}{$\begin{array}{l}\text { Distribution of the patients according to etiology of } \\
\text { fractures }\end{array}$} \\
\hline Type & Frequency & Percentage \\
\hline Fall & 13 & 28.8 \\
\hline RTA & 26 & 57.8 \\
\hline Sports injuries & 3 & 6.7 \\
\hline Violence & 3 & 6.7 \\
\hline Total & 45 & 100.0 \\
\hline
\end{tabular}

\section{DISCUSSION}

Different studies have shown that there are epidemiological differences in the etiology, type, and site of midface fracture and in patient characteristics. Sometimes these fractures may involve other structures like nasal cavity, orbit, maxillary sinus, cranial nerves, major blood vessels and the brain due to close proximity of facial bones with these structures and come up with damaging results. ${ }^{15}$ Previous studies have shown that maxillofacial injuries more frequently affected men than women., ${ }^{4,7}$ Our study also shows that men reported more than women for the treatment of midface fractures. Mean age of our study shows that the patients in third decade of life are the most affected age groups as some earlier reports in the last decade on midfacial fractures also show the patient of third decade of life with the mean of $33.16 \pm 14.0$ years. ${ }^{2,8,9}$

A Road traffic accident being the most frequent cause of midface fractures is reported by several studies. ${ }^{1,5,6}$ Present study supports the findings of these earlier studies showing that road traffic accidents represents $57.8 \%$ of all etiological factors.

As much as $62.3 \%$ of fractures were zygomatic followed by $22.2 \%$ lefort II in this study. Prior studies on midface fractures also showed the high percentage of zygomatic bone involvement. ${ }^{2,10,11}$

\section{CONCLUSION}

This study concludes that although there are many causes of maxillofacial trauma, but in this area road traffic accidents with zygomatic fractures are higher in number followed by other etiologies and bones involved respectively. Also showing involvement of both children and adults that indicates lack of awareness and contravention of traffic regulations.

Furthermore collection of data regarding the 
epidemiology of midfacial fractures is important because it may help healthcare providers to take necessary steps for preventive measures. Also it is very advantageous for public awareness regarding reduction of aggression, violence and helmet usage. Although this study has reached its aims, but there is an unavoidable limitation that the population of the experimental group is small and it is confined to a limited area as well. So by increasing no of participants and covering more areas we can explore more etiological factors regarding midfacial fractures. Also we can able to compare these fractures with other facial fractures like mandibular fractures.

\section{CONFLICT OF INTEREST}

None declared.

\section{REFERENCES}

1. Septa D, Newaskar V P, Agarwal D. Etiology, Incidence and Patterns of Mid-Face Fractures and Associated Ocular Injuries. J Maxillofac Oral Sur, 2014; 13(2): 115-119. https://doi.org/10.1007/s12663-012-0452-9

2. Zaleckas L, Peciuliene V, Gendviliene L. Prevalence and etiology of midfacial fractures: A study of 799 cases open Access funded by The Lithuanian University of Health Sciences.j.medici, 2015; 06.005

3. Udeabor S.E, Akinbami B.O, Yarhere K.S. Maxillofacial Fractures: Etiology, Pattern of Presentation and Treatment in University of Port Harcourt Teaching Hospital, Port Harcourt, Nigeria. Journal of Dental Surgery, 2014; Article ID 850814, 5 pages.

4. Erdogan M, Cabuka E, Çolak S. Epidemiological differences among emergent maxillofacial fractures. J. Exp. Clin. Med, 2013; 30:115-117.

https://doi.org/10.5835/jecm.omu.30.02.005

5. Ram H, Kumar V, Singh RK. Epidemiology of midface fractures: a retrospective study on 729 patients. Article in International Journal of Medical Toxicology and Legal Medicine, 2010; 12(3):48-53.

6. Rehman B, Shah M A, Ansari S R. Characteristics of Maxillofacial Fractures Resulting from Road Traffic Accidents- An Analysis of 250 Patients. Pak Dent Assoc, 2010; 19(3): 158 -163.
7. Devadiga A, Prasad K. Epidemiology of Maxillofacial Fractures and Concomitant Injuries in a Craniofacial Unit: A Retrospective Study. The Internet Journal of Epidemiology. 2007; 5(2):1-7.

8. YkedaI R B A, BallinII C R, Moraes SR. Epidemiological profile of 277 patients with facial fractures treated at the emergency room at the ENT Department of Hospital do Trabalhador in Curitiba/PR, in 2010. Int. Arch. Otorhinolaryngol, 2012; 16 (4):437- 444.

9. Paes J V, SáPaes F L, Valiati R. Retrospective study of prevalence of face fractures in southern Brazil. Indian J Dent Res, 2012; 23:80-6. https://doi.org/10.4103/0970-9290.99045

10. Melek L N, ShararaAA. Retrospective study of maxillofacial trauma in Alexandria University: Analysis of 177 cases. Tanta Dent J, 2016; 13:28-33.

https://doi.org/10.4103/1687-8574.186943

11. Singaram MP, Vijayabala S, UdhayaKumar R K. Pattern, etiology, and management of maxillofacial trauma in a developing country: a retrospective study. J Korean Assoc Oral MaxillofacSurg, 2016; 42(4):174-181.

https://doi.org/10.5125/jkaoms.2016.42.4.174

12. Arslan E D, SolakogluA G, Komut E. Assessment of maxillofacial trauma in emergency department. World J EmergSurg, 2014; 9(1):13. https://doi.org/10.1186/1749-7922-9-13

13. Gail R, Devireddy S K \& Kumar RV. Faciomaxillary fractures in a Semi-urban South Indian Teaching Hospital: A retrospective analysis of 638 cases. Contemp Clin Dent, 2015; 6:539-43.

https://doi.org/10.4103/0976-237X.169847

14. Yamamoto K, Matsusue Y \& horita S. Clinical Analysis of Midfacial Fractures. Mater Sociomed, 2014; 26(1): 21-25.

https://doi.org/10.5455/msm.2014.26.21-25

15. Vyas A, Mazumdar U \& Rajput R.A Comprehensive Retrospective Analysis of Pattern of Midfacial Fractures among Patients of a Dental Institute in Northern India. I J Pre Clin Dent Res, 2014; 1(2):25-29.

16. Banks P. Killey's fractures of mandible. 4thed. Oxford: Bristol, John Wright 1991.

17. Shah SA, Bangash ZQ, Khan TU. The Pattern of Maxillofacial Trauma \& its Management. J Dent Oral DisordTher, 2016 ; 4(4): 1-6. https://doi.org/10.15226/jdodt.2016.00165 


\section{MULTIPLE CHOICE QUESTIONS}

1) Le Fort II fracture is also called:

a) Craniofacial dysfunction

b) Guerin's fracture

c) Pyramidal fracture

d) None of the above

2) The first step in evaluating a head and neck trauma patient is to assess the patient's:
a) Cardiopulmonary stability
b) Neurologic status
c) Soft tissue Lacerations
d) Bleeding

3) What are the common signs and symptoms of fractured zygoma?
a) Battle's sign
b) Infraorbitalparesthesia
c) Occlusion disturbance
d) Supraorbital paresthesia

4) Type of maxillary fractures in which maxilla fractures through maxillary sinus and along the floor of the nose is:
a) Zygomatic fracture
b) Lefort II fracture
c) Pyramidal fracture
d) Lefort I fracture 